\title{
BMJ Open Incidence, trends and risk factors for obstetric massive blood transfusion in China from 2012 to 2019: an observational study
}

\author{
Yanxia Xie, ${ }^{1}$ Juan Liang, ${ }^{1,2}$ Yi Mu, ${ }^{1}$ Zheng Liu, ${ }^{1}$ Yanping Wang, ${ }^{1}$ Li Dai, ${ }^{1,3}$ \\ Xiaohong Li, ${ }^{1}$ Qi Li, ${ }^{1}$ Mingrong Li, ${ }^{1}$ Peiran Chen, ${ }^{1}$ Jun Zhu (D) , ${ }^{1,4}$ Xiaodong Wang ${ }^{2}$
}

To cite: Xie Y, Liang J, Mu Y, et al. Incidence, trends and risk factors for obstetric massive blood transfusion in China from 2012 to 2019: an observational study. BMJ Open 2021;11:e047983. doi:10.1136/ bmjopen-2020-047983

- Prepublication history and additional supplemental material for this paper are available online. To view these files, please visit the journal online (http://dx.doi.org/10.1136/ bmjopen-2020-047983).

$\mathrm{JZ}$ and XW contributed equally

Received 15 December 2020 Accepted 16 September 2021

Check for updates

(c) Author(s) (or their employer(s)) 2021. Re-use permitted under CC BY-NC. No commercial re-use. See rights and permissions. Published by BMJ.

For numbered affiliations see end of article.

\section{Correspondence to}

Prof. Jun Zhu; zhujun028@163.com and

Prof. Xiaodong Wang;

drwangxiaodong@126.com

\section{ABSTRACT}

Objectives This study aims to use the high-quality national monitoring data from the China's National Maternal Near Miss Surveillance System (NMNMSS) to ascertain the incidence, trends and risk factors of obstetric massive blood transfusion (MBT) from 2012 to 2019 in China and determine its clinical outcomes.

Settings Observational study of hospitalised pregnancies who had given birth or ended their pregnancy among member hospitals of NMNMSS.

Participants 11667406 women were included in this study.

Primary and secondary outcome measures We screened for the incidence, trends, risk factors and main reasons for obstetric MBT, and the outcomes after obstetric MBT. MBT was defined as the transfusion of $\geq 5$ units of red blood cells or $\geq 1000 \mathrm{~mL}$ of whole blood. The incidence of MBT was defined as the MBT cases per 10000 pregnancies.

Results Obstetric MBT occurred in 27626 cases, corresponding to an incidence of 23.68 per 10000 maternities, which exhibited an increasing trend in China during 2012-2019 (14.03-29.59 per 10000 maternities, $p$ for trend $<0.001)$. Obstetric MBT was mainly associated with amniotic fluid embolism, uterine atony, abnormal placenta, severe anaemia, ectopic pregnancy, abortion, caesarean section, advanced maternal age and multiparous from biological effect. While from sociological effects, uterine atony, severe anaemia and placenta previa are the top three complications which more likely to undergo obstetric MBT in the Chinese population. Overall, the secular trends of hysterectomy incidence $(25.07 \%$ $9.92 \%)$ and MMR during hospitalisation (21.41\%o-7.48\%o) among women who underwent MBT showed decreasing trends ( $p$ for trend <0.001).

Conclusion To minimise the incidence of obstetric MBT, more attention should be paid to education on the importance of the antenatal visit, evidence-based transfusion practice and females who are multiparous and have an advanced age, amniotic fluid embolism, uterine atony, severe anaemia and placenta previa.

\section{INTRODUCTION}

Obstetric haemorrhage remains a common obstetric emergency and is the leading cause

\section{STRENGTHS AND LIMITATIONS OF THIS STUDY}

$\Rightarrow$ Study was based on a national surveillance data covering 441 hospitals across 30 provinces.

$\Rightarrow$ This study first evaluated the incidence, trends, risk factors and main reasons of obstetric massive blood transfusion (MBT) at national level in China.

$\Rightarrow$ Limitation include the obstetric MBT is a binary variable, which does not allow us for additional analyses.

$\Rightarrow$ Our analysis was also limited to information presented in the National Maternal Near Miss Surveillance System record.

of maternal deaths worldwide, ${ }^{1}$ similarly in China. $^{2}$ In addition to strengthening the patient's uterus contractions, drug haemostasis, surgery, etc, massive blood transfusion (MBT) also plays a key role in the treatment of obstetric haemorrhage. ${ }^{3-6}$ MBT occurs when large volumes of blood products are administered over a short period of time, as a 'maternal near miss event', it signifies major obstetric haemorrhage and requires extensive coordination of the obstetric, anaesthesia and blood bank teams. ${ }^{78}$

The incidence of $\mathrm{MBT}$ in relation to delivery or postpartum haemorrhage $(\mathrm{PPH})$ has been reported to be $2.3-10.0$ per 10000 maternities in high-resource countries, ${ }^{9-13}$ and an increasing trend in the rate of MBT post partum has been reported in Sweden. ${ }^{10}$ However, only two small studies focused on obstetric MBT in China. ${ }^{14}{ }^{15}$. One study concluded that the incidence of MBT in relation to $\mathrm{PPH}$ was stable (25-27 per 10000 maternities) during 2006-2015. Another reported that the MBT rate attributed to $\mathrm{PPH}$ was $0.31 \%$ in women undergoing caesarean delivery. ${ }^{14}$ China's universal two-child policy was announced in October 2015. ${ }^{16}$ Due to the new policy, the characteristics of mothers in China have changed greatly; for example, the 
monthly percentage of multiparous mothers increased by $9.1 \%$ from a baseline mean level of $46.4 \%$, and the monthly mean percentage of older women grew from $8.5 \%$ to $13.5 \% .{ }^{17}$ However, there is no research on obstetrics MBT after the policy was implemented in China. In addition, current studies on MBT are generally limited to $\mathrm{PPH}$, caesarean section or maternal delivery after a certain gestational age. ${ }^{1011} 131418$ There are many other obstetric diseases, such as abortion and ectopic pregnancy, that require MBT, and MBT is not performed only after a specific gestational age. ${ }^{19}{ }^{20}$ Emergency MBT is often needed to save these women. Therefore, it would be extremely helpful for establishing an emergency plan aims to prevent adverse outcomes by exploring the current status, characteristics and potential risk factors of obstetric MBT.

We aim to use the high-quality national monitoring data from the China's National Maternal Near Miss Surveillance System (NMNMSS) during 2012-2019 to determine the incidence and trends of obstetric MBT, the risk factors and main reasons for obstetric MBT, and the adverse outcomes after obstetric MBT.

\section{MATERIALS AND METHODS}

\section{Data sources}

Individual-level data were collected from NMNMSS from 1 January 2012 to 31 December 2019. The NMNMSS system was first established in 2010 and covers 441 health facilities that treated more than 1000 deliveries annually. The included hospitals are located in 326 districts or counties throughout 30 provinces in mainland China, excluding Tibet. The detailed sample methods have been described elsewhere. ${ }^{21-23}$ Within each hospital, sociodemographic and obstetric information were collected from all the pregnant or postpartum women admitted to the obstetric department. The doctors responsible for patient care collected the data, which included the date of delivery, the number of antenatal visits, the maternal education and marital statuses, the maternal age, the gestational age at delivery, the mode of delivery, the number of fetuses and the maternal complications (at any time during hospitalisation), and maternal near miss, including whether obstetric MBT have occurred. The inclusion criteria included the hospitalised pregnancies who had given birth or ended their pregnancy among member hospital of NMNMSS.

Institutional data were collected from each hospital through the NMNMSS in 2012, 2015 and 2018, including information on the hospital (hospital level, type), human resources (number, titles and degrees of the obstetricians) and service capability (whether there is safe blood storage in the hospital, etc).

\section{Definitions}

The usual definitions of maternal age, marital status, number of antenatal care visits, educational level, delivery method, history of caesarean section and parity were used, as detailed elsewhere. ${ }^{22-24}$ Based on the hospital's location, we classified regions as eastern, central or western and the hospital level was defined based on the size of hospital (number of beds, number of doctors and number of equipment), medical service capacity (clinical service and clinical expert available, etc) and the management level of the hospital. ${ }^{24}$ Level 1 represents the smallest hospitals and level 3 the largest.

We defined MBT as the transfusion of $\geq 5$ units of red blood cells or $\geq 1000 \mathrm{~mL}$ of whole blood, ${ }^{25}{ }^{26}$ which is consistent with that used in the WHO multicountry survey on maternal and newborn health, listed in online supplemental appendix 1. Multiple blood component transfusions require transfusion volume conversion, the conversion standard is $200 \mathrm{~mL}$ of plasma/whole blood $=1$ units of red blood cells, while the other blood components were not included in the calculation of total blood transfusion.

Definition of pregnancy complications reference to obstetrics and gynaecology textbooks (eighth edition) used in China. Major complications associated with obstetric MBT were identified based on previously published studies, including obstetric haemorrhage-related conditions and complications that may cause obstetric haemorrhage. ${ }^{9-1115}$ Abortion, ectopic pregnancy, placenta previa, placenta accreta, placenta abruptio, placenta retained, uterine atony, uterine rupture and soft birth canal lacerations were included in the obstetric haemorrhage-related conditions, while hypertensive disorders in pregnancy, Hemolysis elevated liver enzymes and low platelets count syndrome(HELLP syndrome), puerperal infection, amniotic fluid embolism (AFE) and severe anaemia ${ }^{3}$ were included in the complications. Severe anaemia was defined as haemoglobin concentration of $<70 \mathrm{~g} / \mathrm{L}$ and its definition excluded PPH.

In addition, the percentage of safe blood storage was defined as the amount of stored blood that can be guaranteed for general emergency blood use within the time period when the blood sent to the bank or delivered by the blood bank, is generally not less than that needed for 3 days of use. ${ }^{27}$

\section{Statistical methods}

In the study, multiple pregnancies were treated as one case. All statistical calculations were performed using Stata software, V.16.0 (StataCorp). A two-sided $\mathrm{p}<0.05$ was considered statistically significant.

The discrete data were summarised as frequencies and percentages. The $\mathrm{p}$ for trends were determined by logistic regression. Then, we used the $\chi^{2}$ test to examine the differences in distribution between the nulliparous and multiparous women.

Multivariable logistic regression was used to examine the associations between the maternal characteristics, relevant clinical factors and proportion of cases needing obstetric MBT. The findings from two models were reported. Model 1 presented the crude ORs and 95\% CIs, considering the clustering of births within hospitals. 
Model 2 further provided the adjusted ORs (aOR) and 95\% CIs after the model was adjusted for (1) the clustering of births within hospitals; (2) the hospital region, birth location (urban/rural) and hospital level; (3) the mother's education level, marital status, age, parity, antenatal care, gestational week, multiple gestations, the presence of uterine scarring and the delivery method and (4) other major morbidities associated with obstetric MBT.

To identify the main causes of the obstetric MBT at the sociological level, we calculated the population aetiological fraction (PEF).

Population etilogic fraction $(\mathrm{PEF})=\frac{\mathrm{P}(\mathrm{aOR} * 1)}{[\mathrm{P}(\mathrm{aOR}-1)+1]} * 100 \%$

where $P$ is the proportion of cases that are exposed to pregnancy complications and $\mathrm{aOR}$ is the aOR for the effect on obstetric MBT incidence.

\section{Patient and public involvement}

Patients and members of the public were not involved in the design of this study.

\section{RESULTS}

\section{Overall incidence and trends of obstetric MBT}

From 2012 to 2019, 11667406 women who had given birth or ended their pregnancy were included in this study. Obstetric MBT occurred in 27626 cases, corresponding to an incidence of 23.68 per 10000 maternities. As shown in figure 1, the incidence of obstetric MBT increased from 14.03 per 10000 maternities in 2012 to 29.59 per 10000 maternities in 2019 ( $\mathrm{p}$ for trend $<0.001$ ). Similar trends were observed in the east, central and west of China. In addition, 350 health facilities had reported the institutional data for 2012, 2015 and 2018. The overall percentage of safe blood storage increased from 2012 to $2018(77.71 \%-82.57 \%)$, and this increase remained after the data were stratified by hospital level (level 1: $30.61 \%-$ $38.8 \%$; level 2: $78.95 \%-84.74 \%$; level 3: $96.40 \%-98.20 \%$ ) (figure 2).

\section{Subgroup incidence and risk factors of obstetric MBT}

Table 1 displays the incidence and risk of obstetric MBT according to maternal characteristics. Being elderly, a lower level of education, a history of fewer antenatal treatments, uterine scarring, multiparity, having a small gestational age delivery, caesarean section and multiple gestations were associated with a higher risk of needing obstetric MBT. Furthermore, the association between abortion and MBT was strong, with an aOR 1.77 (95\% CI 1.42 to 2.21 ).

As table 2 shows, AFE, placenta accrete and HELLP syndrome had the three highest incidence values for obstetric MBT. The main risk factor for obstetric MBT was AFE, which led to a 127-fold increased risk, with an aOR 126.85 (95\% CI 96.88 to 166.10). Women who had severe anaemia or uterine atony were nearly 36 times more likely to undergo obstetric MBT. We also found abnormal placenta to represent a major risk factor, with an aOR 6.93 (95\% CI 6.05 to 7.94) for placenta previa, 11.65 (95\% CI 9.48 to 14.31) for placenta accrete, 6.53 (95\% CI 5.73 to 7.45 ) for placenta abruptio and 3.01 (95\% CI 2.48 to 3.65) for placenta retained. In addition, compared with non-HELLP syndrome, maternal HELLP syndrome led to a higher risk of needing obstetric MBT. Furthermore, the association between ectopic pregnancy

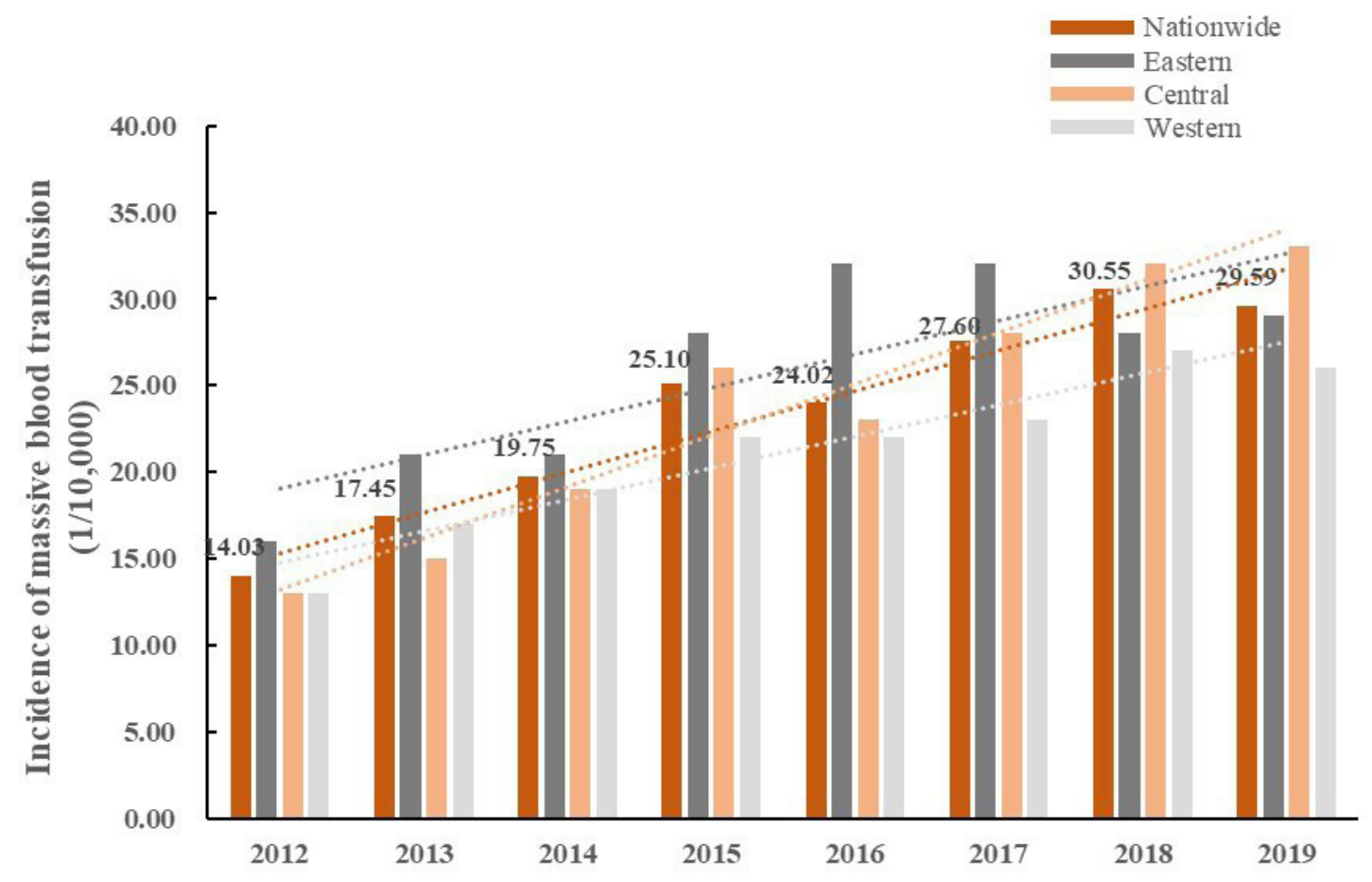

Figure 1 The secular trends and incidence of massive blood transfusion (1/10 000) during 2012-2019. 
- 2012

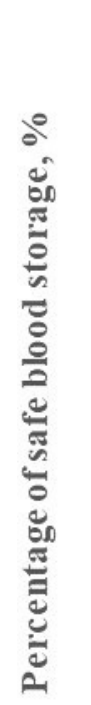

$-2015$

$=2018$ and uterine rupture and obstetric MBT was strong. Moreover, pre-eclampsia or eclampsia, soft birth canal lacerations and puerperal infection were also associated with the incidence of obstetric MBT.

\section{Characteristics of multiparous women}

We further compared the differences in obstetric MBTrelated risk factors in addition hysterectomy and MMR during the hospitalisation between the nulliparous and multiparous women. An advanced maternal age, a lower education level, less antenatal care, abortion, ectopic pregnancy, placental abnormalities, severe anaemia, uterine rupture, AFE, hysterectomy and mortality during hospitalisation were more likely to occur in women who were multiparous (online supplemental appendix table).

\section{Population aetiological fraction for complications}

We calculated the PEF for the different complications to identify the main reasons for obstetric MBT at the population perspective. As table 3 presents, the three highest PEFs were $42.28 \%$ for uterine atony, $12.33 \%$ for severe anaemia and $6.08 \%$ for placenta previa.

\section{Clinical outcomes and trends in the MBT population}

Of the 27626 women, 4010 underwent hysterectomy, and 376 died during the hospitalisation. As shows in figure 3, the trends of hysterectomy (25.07\%-9.92\%) and MMR during hospitalisation (21.41\%o-7.48\%o) from 2012 to 2019 among women who underwent MBT was decrease ( $\mathrm{p}$ for trend $<0.001$ ). A decrease trend in hysterectomy and the MMR during the hospitalisation in level 1 and level 2 hospitals as well as in level 3 hospitals were also observed. As online supplemental appendix figure shows, a greater decline in level hospital and level 2 hospitals for hysterectomy, and a greater decline in level 2 hospitals for maternal mortality rate was observed.

\section{DISCUSSION}

The incidence of obstetric MBT during 2012-2019 was 23.66 per 10000 maternities, and there was an increasing trend in China. An advanced maternal age, uterine scarring, a multiparous status and multiple gestations were associated with a higher risk of needing obstetric MBT. AFE, uterine atony and severe anaemia were major complications associated with obstetric MBT. The top three PEFs were $42.28 \%$ for uterine atony, $12.33 \%$ for severe anaemia and $6.08 \%$ for placenta previa.

Obstetric MBT has been internationally reported in recent years. ${ }^{911-13}$ However, due to differences in the definition of MBT, the incidence of MBT varies greatly across countries; for example, the incidence is 5.3 per 10000 maternities in Sweden, ${ }^{10} 10.0$ per 10000 maternities in New York, ${ }^{9} 6.5$ per 10000 births in the Netherlands ${ }^{13}$ and 2.3 per 10000 maternities in the UK. ${ }^{11}$ The definition of MBT is generally limited to 24 hours after giving birth. However, different amounts of blood, typically 5-10 units of red blood cells, have been used. MBT involves $\geq 10$ units of red blood cells in Sweden and New York ${ }^{9} 10$ and $\geq 8$ units of red blood cells in the UK and Netherlands. ${ }^{113}$ In our study, obstetric MBT was defined as the transfusion of $\geq 5$ units of red blood cells or $\geq 1000 \mathrm{~mL}$ of whole blood. ${ }^{28}$ Despite these differences in the incidence of MBT, the increasing trend is consistent across countries, except in the Netherlands. ${ }^{10} 13$ The incidence of obstetric MBT also showed an increasing trend from 2012 to 2019 in China (14.03 per 10000 maternities to 29.59 
Table 1 The incidence and risk of massive blood transfusion (MBT) among different maternal characteristics ( $\mathrm{N}=11667406)$

\begin{tabular}{|c|c|c|c|c|}
\hline Characteristics & Case/total deliveries & $\begin{array}{l}\text { Incidence of MBT } \\
(1 / 10000)\end{array}$ & $\begin{array}{l}\text { Crude OR* } \\
(95 \% \mathrm{Cl})\end{array}$ & $\begin{array}{l}\text { Adjusted OR† } \\
\text { (95\% Cl) }\end{array}$ \\
\hline \multicolumn{5}{|l|}{ Age (years) } \\
\hline$<20$ & $473 / 287790$ & 16.44 & 1.15 (1.03 to 1.28$)$ & 1.09 (0.97 to 1.21$)$ \\
\hline $20-24$ & $3030 / 2114730$ & 14.33 & reference & reference \\
\hline $25-29$ & $8024 / 4642235$ & 17.28 & 1.21 (1.12 to 1.30$)$ & 0.99 (0.94 to 1.06$)$ \\
\hline $30-34$ & $8116 / 2900510$ & 27.98 & 1.96 (1.77 to 2.16$)$ & 1.05 (0.97 to 1.13$)$ \\
\hline $35-39$ & $5151 / 1125337$ & 45.77 & 3.20 (2.89 to 3.55$)$ & $1.13(1.03$ to 1.24$)$ \\
\hline$\geq 40$ & $1860 / 278675$ & 66.74 & 4.68 (4.23 to 5.19$)$ & $1.24(1.10$ to 1.40$)$ \\
\hline Missing & $972 / 318129$ & 30.55 & 2.14 (1.62 to 2.81$)$ & 1.30 (1.07 to 1.56$)$ \\
\hline \multicolumn{5}{|l|}{ Education } \\
\hline College or higher & 7977/4 315935 & 18.48 & reference & reference \\
\hline High school & 7264/3 118196 & 23.30 & 1.26 (1.08 to 1.48$)$ & 1.25 (1.11 to 1.40$)$ \\
\hline Middle school & $9186 / 3581050$ & 25.65 & 1.39 (1.07 to 1.80$)$ & 1.59 (1.33 to 1.91$)$ \\
\hline Primary school & $1552 / 344874$ & 45.00 & 2.44 (1.97 to 3.02 ) & 1.59 (1.38 to 1.84$)$ \\
\hline Illiteracy & $412 / 60294$ & 68.33 & $3.72(2.76$ to 5.01$)$ & 1.94 (1.56 to 2.40$)$ \\
\hline Missing & $1235 / 247057$ & 49.99 & $2.71(1.24$ to 5.95$)$ & 1.27 (0.76 to 2.12$)$ \\
\hline \multicolumn{5}{|l|}{ Marital status } \\
\hline Unmarried & $639 / 196743$ & 32.48 & 1.38 (1.17 to 1.63$)$ & $1.15(0.95$ to 1.39$)$ \\
\hline Married & 26 979/11468 023 & 23.53 & reference & reference \\
\hline Missing & $8 / 2640$ & 30.30 & 1.29 (0.58 to 2.86$)$ & 1.07 (0.50 to 2.30$)$ \\
\hline \multicolumn{5}{|l|}{ Parity } \\
\hline Nulliparous & $9788 / 6400896$ & 15.29 & reference & reference \\
\hline 1 & $12628 / 4438595$ & 28.45 & 1.86 (1.72 to 2.02$)$ & 1.19 (1.12 to 1.26$)$ \\
\hline 2 & $5142 / 810139$ & 63.47 & 4.17 (3.64 to 4.78$)$ & 1.83 (1.65 to 2.03$)$ \\
\hline Missing & $68 / 17776$ & 38.25 & 2.51 (0.53 to 11.91$)$ & 0.66 (0.13 to 3.48$)$ \\
\hline \multicolumn{5}{|l|}{ Antenatal care } \\
\hline None & $1802 / 253698$ & 71.03 & 4.45 (3.00 to 6.61$)$ & 1.99 (1.40 to 2.82$)$ \\
\hline $1-3$ & $3512 / 947952$ & 37.05 & $2.32(1.75$ to 3.06$)$ & $1.49(1.18$ to 1.88$)$ \\
\hline $4-6$ & 7217/3 193661 & 22.60 & $1.41(1.14$ to 1.74$)$ & $1.44(1.23$ to 1.69$)$ \\
\hline $7-9$ & 7038/3 390343 & 20.76 & 1.30 (1.06 to 1.58$)$ & 1.31 (1.11 to 1.54$)$ \\
\hline$\geq 10$ & $5621 / 3504970$ & 16.04 & reference & reference \\
\hline Missing & $2436 / 376782$ & 64.65 & 4.05 (2.91 to 5.64$)$ & 1.55 (1.22 to 1.96$)$ \\
\hline \multicolumn{5}{|l|}{ Birth location } \\
\hline City & $20316 / 6985253$ & 29.08 & 1.87 (1.43 to 2.43$)$ & 1.36 (1.04 to 1.78$)$ \\
\hline Rural & $7310 / 4682153$ & 15.61 & reference & reference \\
\hline \multicolumn{5}{|l|}{ Previous scar } \\
\hline No & $17804 / 9736123$ & 18.29 & reference & reference \\
\hline Yes & 9719/1908 222 & 50.93 & 2.79 (2.54 to 3.08 ) & 1.35 (1.24 to 1.46$)$ \\
\hline Missing & $103 / 23061$ & 44.66 & 2.45 (0.75 to 8.00$)$ & 1.30 (0.74 to 2.27$)$ \\
\hline \multicolumn{5}{|l|}{ Region } \\
\hline East & $8762 / 3366371$ & 26.03 & 1.23 (0.85 to 1.79$)$ & 1.75 (1.29 to 2.37 ) \\
\hline Central & $11075 / 4621694$ & 23.96 & $1.13(0.84$ to 1.53$)$ & 1.75 (1.31 to 2.33 ) \\
\hline West & $7789 / 3679341$ & 21.17 & reference & reference \\
\hline \multicolumn{5}{|l|}{ Hospital level } \\
\hline Level 1 & $1225 / 1297341$ & 9.44 & reference & reference \\
\hline
\end{tabular}


Table 1 Continued

\begin{tabular}{|c|c|c|c|c|}
\hline Characteristics & Case/total deliveries & $\begin{array}{l}\text { Incidence of MBT } \\
(1 / 10000)\end{array}$ & $\begin{array}{l}\text { Crude OR* } \\
(95 \% \mathrm{Cl})\end{array}$ & $\begin{array}{l}\text { Adjusted OR† } \\
(95 \% \mathrm{Cl})\end{array}$ \\
\hline Level 2 & $8940 / 5298378$ & 16.87 & 1.79 (1.31 to 2.44$)$ & 1.22 (0.85 to 1.73$)$ \\
\hline \multicolumn{5}{|c|}{ Multiple gestations } \\
\hline No & $24973 / 11422786$ & 21.86 & reference & reference \\
\hline Missing & $392 / 28926$ & 135.52 & 6.27 (3.93 to 10.01$)$ & 1.34 (0.86 to 2.08$)$ \\
\hline \multicolumn{5}{|l|}{ Gestational week } \\
\hline$<28$ & $3048 / 490420$ & 62.15 & 4.25 (3.57 to 5.06 ) & 2.06 (1.59 to 2.66$)$ \\
\hline 28-32 & $2313 / 167840$ & 137.81 & 9.49 (8.44 to 10.67$)$ & 2.21 (1.94 to 2.51 ) \\
\hline 33-36 & $6413 / 655802$ & 97.79 & $6.71(6.04$ to 7.45$)$ & 1.78 (1.64 to 1.93$)$ \\
\hline Missing & $701 / 49801$ & 140.76 & 9.70 (6.52 to 14.42$)$ & 4.83 (3.67 to 6.36$)$ \\
\hline \multicolumn{5}{|l|}{ Mode of delivery } \\
\hline Vaginal & $5676 / 6167464$ & 9.20 & reference & reference \\
\hline CS & $18551 / 4998004$ & 37.12 & 4.04 (3.93 to 4.17$)$ & 2.08 (1.89 to 2.28$)$ \\
\hline Abortion & $3349 / 498143$ & 67.23 & 7.35 (7.04 to 7.67$)$ & 1.77 (1.42 to 2.21$)$ \\
\hline Missing & $50 / 3795$ & 131.75 & 14.49 (10.95 to 19.18$)$ & 0.73 (0.34 to 1.57$)$ \\
\hline
\end{tabular}

${ }^{*}$ Adjusted for the clustering of births within hospitals.

†Adjusted for: the clustering of births within hospitals; region; hospital level; antenatal care; birth location; multiple gestations; gestational week; mother's education, marital status, age and parity; the delivery method and other factors thought to be associated with massive blood transfusion, such as a placenta previa; placenta accrete; placenta abruptio; placenta retained; all hypertensive disorders in pregnancy; hemolysis elevated liver enzymes and low platelets count syndrome (HELLP syndrome); severe anaemia; uterine atony; ruptured uterus; soft birth canal lacerations; puerperal infection and amniotic fluid embolism.

$\mathrm{Cl}$, confidence interval; CS, caesarean section; OR, odds ratio.

per 10000 maternities). Regarding excessive maternal bleeding, if there are no adequate blood resources, it is difficult to save the mother's life. ${ }^{29}$ Our results showed that the percentage of safe blood storage at level 3 hospitals in 2012 was $96.4 \%$, while that at level 1 hospitals was $30.6 \%$. In recent years, primary medical institutions have been increasingly constructed in China. ${ }^{30}$ In addition, the rate of blood supply in China showed a steadily increasing trend (from 1.23 to 1.74 units per 1000 population) from 2012 to $2014 .{ }^{31}$ As a result, the percentage of safe blood storage increased the most in level 1 hospitals increasing from $30.6 \%$ to $38.8 \%$ during 2012-2018. In addition, educational awareness to patients and clinicians on optimal blood utilisation practices, and relatively better access to blood products or implementation of a protocol for the management of massive obstetric haemorrhage both contributed to the rising trend of MBT.

The increased incidence of MBT plays a key role in reducing adverse outcomes in pregnancies. On the one hand, it is possible to prevent the occurrence of maternal deaths. From 2012 to 2019, the MMR due to obstetric haemorrhage with MBT in nationwide hospitals showed a decreasing trend (decreased by 68.8\%), and the magnitude of decrease was larger than that in the population-based obstetric haemorrhage MMR reported by National Maternal Death Monitoring during the same period $(54.6 \%) .^{32}$ On the other hand, the uterus can be saved by timely MBT. When severe obstetric haemorrhage fails to respond to other treatments, hysterectomy is usually performed. Although an increased hysterectomy rate was found among the MBT women in Sweden, we found a decreasing trend in Chinese women. Retaining the uterus can not only realise their dream of becoming a mother but also preserve their quality of life. This trend was observed at all three levels (level 1-level 3).

Every woman who needs obstetric MBT might have a fatal obstetric haemorrhage, and the slightest error in treatment can kill them before they undergo blood transfusion. Therefore, recognising the possible risk factors for MBT and preventing their occurrence are effective strategies to ensure the safety of women. We found that higher parity is associated with an increased risk of needing obstetric MBT. In our study, advanced maternal age, lower education level, less antenatal care and obstetric haemorrhage-related conditions were more likely to occur in women who were multiparous. Of course, these factors are also positively associated with obstetric MBT. Due to the new fertility policy, the characteristics of 
Table 2 The incidence and risk of mass transfusion (MBT) among different complications ( $N=11667406)$

\begin{tabular}{|c|c|c|c|c|}
\hline Characteristics & Cases & $\begin{array}{l}\text { Incidence of MBT } \\
(1 / 1000)\end{array}$ & $\begin{array}{l}\text { Crude OR* } \\
(95 \% \mathrm{Cl})\end{array}$ & $\begin{array}{l}\text { Adjusted OR† } \\
(95 \% \mathrm{Cl})\end{array}$ \\
\hline Ectopic pregnancy $\ddagger$ & 45648 & 33.52 & 15.41 (12.02 to 19.76$)$ & 9.70 (7.57 to 12.42$)$ \\
\hline \multicolumn{5}{|l|}{ Placenta abnormal } \\
\hline Placenta praeviał & 126105 & 61.56 & 38.054 (33.79 to 42.85 ) & $6.93(6.05$ to 7.94$)$ \\
\hline Placenta accretał & 21545 & 157.53 & 89.68 (70.31 to 114.39$)$ & 11.65 (9.48 to 14.31$)$ \\
\hline Placenta abruptioł & 54460 & 47.26 & 22.95 (19.45 to 27.07$)$ & 6.53 (5.73 to 7.45$)$ \\
\hline Placenta retained§ & 141113 & 24.83 & 12.14 (9.93 to 14.85$)$ & 3.01 (2.48 to 3.65$)$ \\
\hline \multicolumn{5}{|l|}{ Hypertensive disorders } \\
\hline Chronic hypertension $\ddagger$ & 37732 & 4.51 & 1.91 (1.59 to 2.29) & 1.27 (1.04 to 1.55$)$ \\
\hline Gestational hypertension $\ddagger$ & 158526 & 4.88 & 2.10 (1.89 to 2.32$)$ & 1.62 (1.46 to 1.79$)$ \\
\hline Superimposed pre-eclampsiał & 11951 & 8.53 & 3.64 (2.90 to 4.56$)$ & 1.32 (0.99 to 1.74$)$ \\
\hline Pre-eclampsia or eclampsiał & 257096 & 10.53 & 4.86 (4.43 to 5.33$)$ & 2.23 (2.05 to 2.43 ) \\
\hline HELLP syndromeł & 6702 & 92.36 & 43.83 (36.12 to 53.19$)$ & 13.02 (10.58 to 16.02$)$ \\
\hline Severe anaemiał & 46898 & 76.17 & 39.75 (35.30 to 44.75$)$ & 36.00 (32.09 to 40.41$)$ \\
\hline Uterine atony§ & 240063 & 49.65 & 37.95 (31.97 to 45.05$)$ & 36.45 (30.88 to 43.04$)$ \\
\hline Uterine rupture§ & 22748 & 36.09 & 16.23 (11.76 to 22.39$)$ & 5.05 (3.67 to 6.95$)$ \\
\hline Soft birth canal lacerations§ & 127320 & 7.61 & 3.31 (2.36 to 4.65$)$ & 4.28 (3.31 to 5.54$)$ \\
\hline Puerperal infection§ & 13468 & 33.71 & $14.93(12.25$ to 18.20$)$ & 3.47 (2.78 to 4.34$)$ \\
\hline Amniotic fluid embolism§ & 1558 & 411.42 & 301.49 (245.43 to 370.37$)$ & 126.85 (96.88 to 166.10$)$ \\
\hline
\end{tabular}

*Adjusted for the clustering of births within hospitals.

†Adjusted for: the clustering of births within hospitals; region; hospital level; antenatal care; birth location; multiple gestations; gestational week; mother's education, marital status, age and parity; the delivery method and other factors thought to be associated with massive blood transfusion, such as a placenta previa; placenta accrete; placenta abruptio; placenta retained; all hypertensive disorders in pregnancy; HELLP syndrome; severe anaemia; uterine atony; ruptured uterus; soft birth canal lacerations; puerperal infection and amniotic fluid embolism. $\ddagger$ Prenatal factors were included in model 2

§Prenatal and postnatal factors were included in model 2

$\mathrm{Cl}$, confidence interval; HELLP syndrome, Hemolysis elevated liver enzymes and low platelets count syndrome; OR, odds ratio.

Chinese maternal population have changed greatly. ${ }^{16} 17$ In our study, $44.99 \%$ of women were multiparous, among whom $36.35 \%$ had uterine scars, which may be related to the high caesarean section rate during the one-child policy $(46.2 \%){ }^{33}$ Uterine scarring is associated with an increase in the risk of abnormal placenta, infection and uterine rupture. ${ }^{34}{ }^{35}$ Women with these complications may experience extremely large volumes of blood loss during or soon after delivery, ranging from $2000 \mathrm{~mL}$ to $6000 \mathrm{~mL}^{3637}$

In agreement with previous studies, we found that uterine atony, abnormal placenta, uterine rupture and pre-eclampsia were strongly associated with obstetric MBT. ${ }^{9}{ }^{10}$ However, we also found that AFE was the main risk factor for obstetric MBT (aOR 126.85, 95\% CI 96.88 to 166.10). AFE, although rare, remains one of the leading direct causes of maternal mortality in high-income countries, and its management principles include the active correction of coagulation disorders, the aggressive treatment of uterine atony and the use of high-dose glucocorticoids as early as possible. ${ }^{38}{ }^{39}$ The total incidence of AFE was 13.4 per 100000 maternities in our study, which was higher than that previously reported (1.7-7.7 per 100000 maternities). ${ }^{38} 40$ This finding may explain why AFE is considered the primary risk factor for obstetric MBT in our study.

Our study also showed that women with severe anaemia, abortion or ectopic pregnancy were at a higher risk of needing obstetric MBT. Severe anaemia has been associated with an increased prevalence of PPH. ${ }^{41}{ }^{42}$ Similarly, our study showed that severe anaemia increases the risk of needing obstetric MBT by 36 -fold (OR 36.00 , 95\% CI 32.09 to 40.41 ). No studies have focused on ectopic pregnancy, abortion. We found that the association between ectopic pregnancy and MBT was strong, with an aOR of 9.70 (95\% CI 7.57 to 12.42), and maternal abortion showed a relatively weaker association with the risk of needing obstetric MBT (aOR 1.77, 95\% CI 1.42 to 2.21). Both of them often occur at young gestational ages and may put the woman at risk of intraperitoneal bleeding or related complications in the short term and can even lead to death. ${ }^{43}$

However, the OR reflects only the biological effect of a certain disease, while PEF integrates information about the effect estimate's magnitude with information about the prevalence of the disease and can reflect sociological 
Table 3 Population aetiological fraction (PEF) for complications

\begin{tabular}{|c|c|c|c|}
\hline & No & $\begin{array}{l}\text { Prevalence }(1 / 10 \\
000)\end{array}$ & PEF (95\% Cl) \\
\hline Abortion & 498143 & 426.95 & $3.18 \%(1.76$ to $4.91 \%)$ \\
\hline Placenta praevia & 126105 & 108.08 & $6.08 \%(5.18 \%$ to $6.98 \%)$ \\
\hline Placenta accreta & 21545 & 18.47 & $1.93 \%(1.54 \%$ to $2.41 \%)$ \\
\hline Placenta retained & 141113 & 120.95 & $2.37 \%(1.76 \%$ to $3.09 \%)$ \\
\hline Chronic hypertension & 37732 & 32.34 & $0.09 \%(0.01 \%$ to $0.18 \%)$ \\
\hline Gestational hypertension & 158526 & 135.87 & $0.84 \%(0.62 \%$ to $1.06 \%)$ \\
\hline Superimposed pre-eclampsia & 11951 & 10.24 & $0.03 \%(0 \%$ to $0.08 \%)$ \\
\hline Pre-eclampsia or eclampsia & 257096 & 220.35 & $2.64 \%(2.26 \%$ to $3.05 \%)$ \\
\hline Uterine rupture & 22748 & 19.50 & $0.78 \%(0.52 \%$ to $1.15 \%)$ \\
\hline Soft birth canal lacerations & 127320 & 109.12 & $3.46 \%(2.46 \%$ to $4.72 \%)$ \\
\hline Puerperal infection & 13468 & 11.54 & $0.28 \%(0.21 \%$ to $0.38 \%)$ \\
\hline Amniotic fluid embolism & 1558 & 1.34 & $1.65 \%(1.26 \%$ to $2.16 \%)$ \\
\hline
\end{tabular}

HELLP syndrome, Hemolysis elevated liver enzymes and low platelets count syndrome.

effects. Our data were retrieved from a facility-based surveillance system, which covered almost all of China, excluding Tibet. Routinely calculating complicationspecific PEFs will allow us to identify the populations most affected for targeted interventions. The top three complications according to the PEFs were uterine atony, severe anaemia and placenta previa in the Chinese population. Women with such complications should be highly concerned because these complications have a high prevalence in Chinese mothers, and they also lead to a high risk of needing obstetric MBT. Although AFE leads to the

(A)

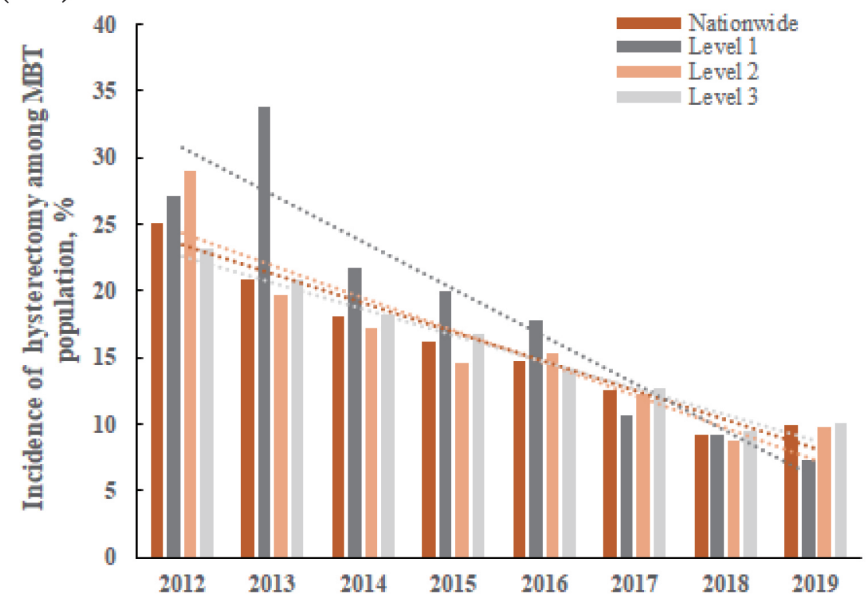

highest risk of obstetric MBT, its PEF was low due to its relatively low maternal incidence. Our findings indicated that it is necessary to focus on the tertiary prevention of uterine atony, severe anaemia, and placenta previa to reduce the risk of needing obstetric MBT in China and minimise the occurrence of adverse maternal outcomes.

The main strength is that we included all women who had given birth or ended their pregnancy during 20122019 from a large nationwide data in China. However, the retrospective nature of the study by itself is a limiting factor as access to all clinical and transfusion variables
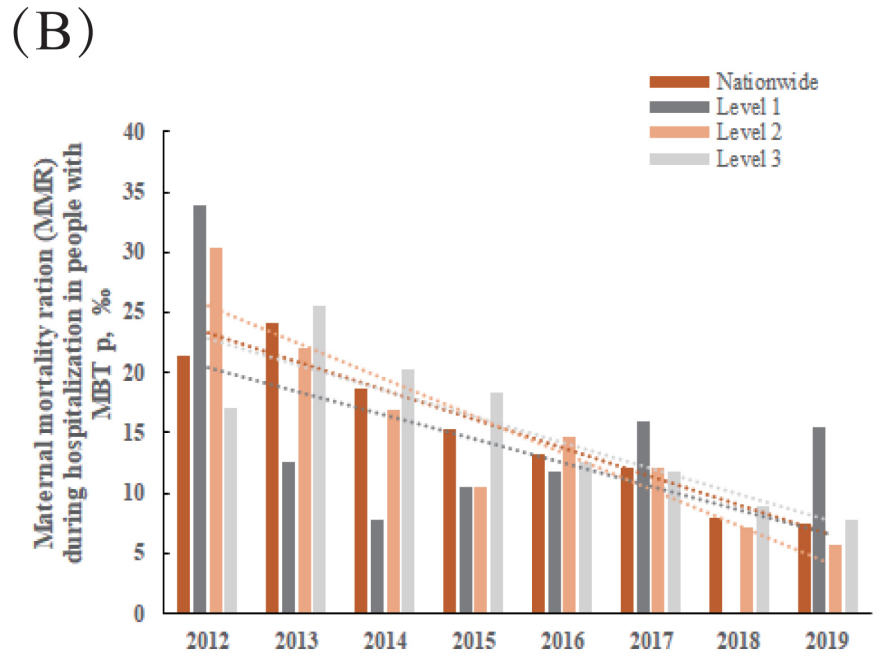

Figure 3 The secular trends and incidence of hysterectomy (\%) (A) and maternal mortality ratio during hospitalisation (\%) (B) among MBT population during 2012-2019. MBT, massive blood transfusion. 
are not possible. The major limitation is the lack of availability of data on many confounding variables that may influence the MBT or adverse outcomes, and the lack of a specific blood transfusion volume limits our ability to conduct additional analyses. In addition, although we recorded the types of blood transfusions performed, we could not use the data for analysis due to the lack of quantitative information.

\section{CONCLUSION}

The incidence of obstetric MBT is increasing in China, but the hysterectomy rate and MMR are decreasing among women undergoing MBT. To minimise the incidence of obstetric MBT, more attention should be paid to education on the importance of the antenatal visit, evidencebased transfusion practice, multiparous women with an advanced age, AFE, uterine atony, severe anaemia and placenta previa. Appropriate blood transfusion preparations and the antenatal early identification for high-risk women might improve the outcomes and reduce the adverse outcomes.

\section{Author affiliations}

${ }^{1}$ National Office for Maternal and Child Health Surveillance of China, Sichuan University West China Second University Hospital, Chengdu, Sichuan, China ${ }^{2}$ Department of Obstetrics, Sichuan University West China Second University Hospital, Chengdu, Sichuan, China

${ }^{3}$ Medical Big Data Center, Sichuan University, Chengdu, Sichuan, China

${ }^{4}$ Key Laboratory of Birth Defects and Related Diseases of Women and Children (Sichuan University), Ministry of Education, Chengdu, Sichuan, China

Acknowledgements We thank the institutions and staff of the National Maternal Near Miss Surveillance System for data collection.

Contributors All authors have contributed to the conduction of this study. YX, $X W, J L$ and $J Z$ developed the study design with contributions from all authors. YX performed the statistical analysis and drafted the manuscript with support from JZ, $X W$ and JL. YM, ML, YW, LD, XL, ML, QL, ZL and PC participated in reviewing, editing and revising the manuscript.

Funding This study was supported by the National Key R\&D Program of China (grant No. 2019YFC1005100), the National Health Commission of the People's Republic of China, the China Medical Board (grant No. 11-065), the WHO (grant No. CHN-12-MCN-004888) and UNICEF (grant No. 2016EJH016).

Competing interests None declared.

Patient consent for publication Not applicable.

Ethics approval Ethical approval for the NMNMSS was provided by the Ethics Committee of West China Second University Hospital, Sichuan University, China. Informed consent from the patient was waived from the Ethics Committee, as the data used in this study were obtained from a national routine surveillance system established by the government. Data use was authorised by the National Health Commission, and data provided to us were de-identified.

Provenance and peer review Not commissioned; externally peer reviewed.

Data availability statement Data are available on reasonable request. The datasets generated and/or analysed during the current study are not publicly available due to the terms of our contract with the Chinese National Health Commission but are available from the corresponding author on reasonable request.

Supplemental material This content has been supplied by the author(s). It has not been vetted by BMJ Publishing Group Limited (BMJ) and may not have been peer-reviewed. Any opinions or recommendations discussed are solely those of the author(s) and are not endorsed by BMJ. BMJ disclaims all liability and responsibility arising from any reliance placed on the content. Where the content includes any translated material, BMJ does not warrant the accuracy and reliability of the translations (including but not limited to local regulations, clinical guidelines, terminology, drug names and drug dosages), and is not responsible for any error and/or omissions arising from translation and adaptation or otherwise.

Open access This is an open access article distributed in accordance with the Creative Commons Attribution Non Commercial (CC BY-NC 4.0) license, which permits others to distribute, remix, adapt, build upon this work non-commercially, and license their derivative works on different terms, provided the original work is properly cited, appropriate credit is given, any changes made indicated, and the use is non-commercial. See: http://creativecommons.org/licenses/by-nc/4.0/.

ORCID iD

Jun Zhu http://orcid.org/0000-0001-9666-8010

\section{REFERENCES}

1 Say L, Chou D, Gemmill A, et al. Global causes of maternal death: a who systematic analysis. Lancet Glob Health 2014;2:e323-33.

2 Yang Y-Y, Fang Y-H, Wang X, et al. A retrospective cohort study of risk factors and pregnancy outcomes in 14,014 Chinese pregnant women. Medicine 2018;97:e11748.

3 Dahlke JD, Mendez-Figueroa H, Maggio L, et al. Prevention and management of postpartum hemorrhage: a comparison of 4 national guidelines. Am J Obstet Gynecol 2015;213:76.e1-76.e10.

4 Pacheco LD, Saade GR, Costantine MM, et al. The role of massive transfusion protocols in obstetrics. Am J Perinatol 2013;30:1-4.

5 Pacheco LD, Saade GR, Costantine MM, et al. An update on the use of massive transfusion protocols in obstetrics. Am J Obstet Gynecol 2016;214:340-4.

6 Kogutt BK, Vaught AJ. Postpartum hemorrhage: blood product management and massive transfusion. Semin Perinatol 2019;43:44-50.

7 Donaldson MD, Seaman MJ, Park GR. Massive blood transfusion. $\mathrm{Br}$ $J$ Anaesth 1992;69:621-30.

8 Zatta AJ, McQuilten ZK, Mitra B, et al. Elucidating the clinical characteristics of patients captured using different definitions of massive transfusion. Vox Sang 2014;107:60-70.

9 Mhyre JM, Shilkrut A, Kuklina EV, et al. Massive blood transfusion during hospitalization for delivery in New York state, 1998-2007. Obstet Gynecol 2013;122:1288-94.

10 Thurn L, Wikman A, Westgren M, et al. Massive blood transfusion in relation to delivery: incidence, trends and risk factors: a populationbased cohort study. BJOG 2019;126:1577-86.

11 Green L, Knight M, Seeney FM, et al. The epidemiology and outcomes of women with postpartum haemorrhage requiring massive transfusion with eight or more units of red cells: a national cross-sectional study. BJOG 2016;123:2164-70.

12 Halmin M, Chiesa F, Vasan SK, et al. Epidemiology of massive transfusion: a binational study from Sweden and Denmark. Crit Care Med 2016;44:468-77.

13 Ramler PI, van den Akker T, Henriquez DDCA, et al. Women receiving massive transfusion due to postpartum hemorrhage: a comparison over time between two nationwide cohort studies. Acta Obstet Gynecol Scand 2019;98:795-804.

14 Bao Y, Xu C, Qu X, et al. Risk factors for transfusion in cesarean section deliveries at a tertiary hospital. Transfusion 2016;56:2062-8.

$15 \mathrm{Hu}$ J, Yu Z-P, Wang P, et al. Clinical analysis of postpartum hemorrhage requiring massive transfusions at a tertiary center. Chin Med J 2017;130:581-5.

16 Zeng Y, Hesketh T. The effects of China's universal two-child policy. Lancet 2016;388:1930-8.

17 Li H-T, Xue M, Hellerstein S, et al. Association of China's universal two child policy with changes in births and birth related health factors: national, descriptive comparative study. BMJ 2019;366:14680.

18 Akinlusi FM, Rabiu KA, Durojaiye IA, et al. Caesarean delivery-related blood transfusion: correlates in a tertiary hospital in Southwest Nigeria. BMC Pregnancy Childbirth 2018;18:24.

19 Jurkovic D, Overton C, Bender-Atik R. Diagnosis and management of first trimester miscarriage. BMJ 2013;346:f3676.

20 Diagnosis and management of ectopic pregnancy: Green-top guideline No. 21. BJOG 2016;123:e15-55.

$21 \mathrm{Mu}$ Y, Wang X, Li X, et al. The National maternal near miss surveillance in China: a facility-based surveillance system covered 30 provinces. Medicine 2019;98:e17679.

22 Liang J, Mu Y, Li X, et al. Relaxation of the one child policy and trends in caesarean section rates and birth outcomes in China between 2012 and 2016: observational study of nearly seven million health facility births. BMJ 2018;360:k817. 
23 Xiong T, Mu Y, Liang J, et al. Hypertensive disorders in pregnancy and stillbirth rates: a facility-based study in China. Bull World Health Organ 2018;96:531-9.

24 Zhu J, Liang J, Mu Y, et al. Sociodemographic and obstetric characteristics of stillbirths in China: a census of nearly 4 million health facility births between 2012 and 2014. Lancet Glob Health 2016;4:e109-18.

25 Souza JP, Gülmezoglu AM, Vogel J, et al. Moving beyond essential interventions for reduction of maternal mortality (the who multicountry survey on maternal and newborn health): a crosssectional study. Lancet 2013;381:1747-55.

26 Say L, Souza JP, Pattinson RC, et al. Maternal near miss--towards a standard tool for monitoring quality of maternal health care. Best Pract Res Clin Obstet Gynaecol 2009;23:287-96.

27 Surveillance TNOoMaCH. Monitoring work manual of China maternal near miss surveillance system, 2016. Available: https://wzycf. mchscn.cn/Main.aspx

28 Souza JP, Gülmezoglu AM, Carroli G, et al. The world Health organization multicountry survey on maternal and newborn health: study protocol. BMC Health Serv Res 2011;11:286.

29 Tanaka H, Matsunaga S, Yamashita T, et al. A systematic review of massive transfusion protocol in obstetrics. Taiwan J Obstet Gynecol 2017:56:715-8

30 Mukamel DB, Zwanziger J, Bamezai A. Hospital competition, resource allocation and quality of care. BMC Health Serv Res 2002;2:10.

31 Liang XH, Zhou SH, Fan YX, et al. A survey of the blood supply in China during 2012-2014. Transfus Med 2019;29:28-32.

32 Commission NH. National health statistics yearbook 2020. Beijing: Peking Union Medical College Press, 2020.

33 Lumbiganon P, Laopaiboon M, Gülmezoglu AM, et al. Method of delivery and pregnancy outcomes in Asia: the who global survey on maternal and perinatal health 2007-08. Lancet 2010;375:490-9.

34 Dodd JM, Crowther CA, Huertas E, et al. Planned elective repeat caesarean section versus planned vaginal birth for women with a previous caesarean birth. Cochrane Database Syst Rev 2013:Cd004224.

35 Marshall NE, Fu R, Guise J-M. Impact of multiple cesarean deliveries on maternal morbidity: a systematic review. Am J Obstet Gynecol 2011;205:262.e1-262.e8.

36 Shainker S, Shamshirsaz A, Haviland M, et al. Utilization and outcomes of massive transfusion protocols in women with and without invasive placentation. J Matern Fetal Neonatal Med 2020;33:3614-8.

37 Wright JD, Pri-Paz S, Herzog TJ, et al. Predictors of massive blood loss in women with placenta accreta. Am J Obstet Gynecol 2011;205:38.e1-38.e6.

38 Fitzpatrick KE, Tuffnell D, Kurinczuk JJ, et al. Incidence, risk factors, management and outcomes of amniotic-fluid embolism: a population-based cohort and nested case-control study. BJOG 2016;123:100-9.

39 Society for Maternal-Fetal Medicine (SMFM). Electronic address: pubs@smfm.org, Pacheco LD, Saade G, et al. Amniotic fluid embolism: diagnosis and management. Am J Obstet Gynecol 2016;215:B16-24.

40 Knight M, Berg C, Brocklehurst P, et al. Amniotic fluid embolism incidence, risk factors and outcomes: a review and recommendations. BMC Pregnancy Childbirth 2012;12:7.

41 Rukuni R, Bhattacharya S, Murphy MF, et al. Maternal and neonatal outcomes of antenatal anemia in a Scottish population: a retrospective cohort study. Acta Obstet Gynecol Scand 2016;95:555-64.

42 Daru J, Zamora J, Fernández-Félix BM, et al. Risk of maternal mortality in women with severe anaemia during pregnancy and post partum: a multilevel analysis. Lancet Glob Health 2018;6:e548-54.

43 Mummert T, Gnugnoli DM. Ectopic pregnancy. StatPearls. Treasure Island (FL): StatPearls Publishing, 2020. 